\title{
Mudanças climáticas e a Divulgação Científica: uma análise das Revistas Ciência Hoje e Superinteressante
}

\author{
Climate changes and Scientific Dissemination: an analysis of Ciência \\ Hoje and Superinteressante magazines
}

\author{
Bruna Sarpa Miceli ; Igor Leandro A. de Carvalho ${ }^{2}$ Ingrid Valadares Carmona $^{3}$; \\ Marcelo Borges Rocha ${ }^{4}$
}

1 Mestre em Ciência, Tecnologia e Educação - PPCTE/ CEFET/RJ, Centro Federal de Educação Tecnológica Celso Suckow da Fonseca (CEFET/RJ), Rio de Janeiro, RJ, Brasil- brunasm213@gmail.com / ORCID: https://orcid.org/0000-0002-6080$\underline{0427}$

2 Mestre em Ciência, Tecnologia e Educação - PPCTE/ CEFET/RJ, Centro Federal de Educação Tecnológica Celso Suckow da Fonseca (CEFET/RJ), Rio de Janeiro, RJ, Brasil- igor.leandro@yahoo.com.br / ORCID: https://orcid.org/0000-0002$\underline{4178-4660}$

3 Mestre em Ciência, Tecnologia e Educação - PPCTE/ CEFET/RJ, Centro Federal de Educação Tecnológica Celso Suckow da Fonseca (CEFET/RJ), Rio de Janeiro, RJ, Brasil- ingrid_valadares@ hotmail.com

4 Doutor em Ciências Biológicas (Zoologia) pela Universidade Federal do Rio de Janeiro (UFRJ), Centro Federal de Educação Tecnológica Celso Suckow da Fonseca (CEFET/RJ), Rio de Janeiro, RJ, Brasil- rochamarcelo36@yahoo.com.br / ORCID: http://orcid.org/0000-0003-4472-7423

\section{Recebido em Dezembro/2017. Publicado em Abril/2020}

Palavras-chave: Mudanças climáticas. Divulgação Científica. Revistas científicas. Mídia impressa. Textos de Divulgação Científica.

Keywords: Climate changes. Scientific Dissemination.
RESUMO: A Divulgação Científica (DC) desempenha um papel fundamental na aproximação do conhecimento científico para a população e está presente em diversos meios de comunicação, inclusive na mídia impressa. Estes textos de DC, ao abordarem questões relacionadas às mudanças climáticas que estão sendo debatidas na atualidade, contribuem para a formação de leitores críticos. Desta forma, questionou-se de que forma as revistas Ciência Hoje e Superinteressante têm abordado os conteúdos referentes a esse tema. O objetivo deste artigo é investigar a forma como estas duas revistas apresentam estes conteúdos durante o período de 2013 a 2016. Foram selecionados um total de 30 textos analisados de acordo com a seção, autoria, imagens, linguagem e precisão científica. Os resultados obtidos divergiram principalmente no que diz respeito à autoria e precisão científica, uma vez que a revista Ciência Hoje, em sua maioria, foi redigida por especialistas, com conteúdos maiores e com maior precisão científica quando comparada com a Superinteressante. Já em relação às imagens e à linguagem, as revistas apresentaram pontos semelhantes em seus conteúdos. Conclui-se, portanto, que as revistas analisadas deram certo destaque ao tema mudanças climáticas em suas edições e que se constituem como potenciais recursos para a divulgação das questões ambientais para o público em geral.

ABSTRACT: Scientific Dissemination (SD) is an important resource to bring the scientific knowledge to a population and it can be found in various media, including the print media. These SD texts, that address climate change issues being debated 
Scientific magazines. Print media. Scientific dissemination texts. today, contribute to the formation of critical readers. In this sense, we questioned the way of two SD magazines- Ciência Hoje and Superinteressante -present the contents to refer to this theme. The purpose of this article is to investigate a way that these two magazines present the climate change contents during the period 2013 to 2016. Thirty texts were selected according to the section, authorship, images, language and scientific precision. The results obtained diverged, especially about the analysis of authorship and scientific precision. The magazine Ciência Hoje, for the most part, was written by specialists, with larger contents and with greater scientific precision when compared to Superinteressante magazine. Regarding to the images and the language, both presented the same points in its contents. We concluded that the Ciência Hoje and Superinteressante drew to our attention to the theme 'climate changes' in their editions and that constitute as potential resources for dissemination of environmental issues to the public.

\section{INTRODUÇÃO}

A Divulgação Científica (DC) constitui-se de ferramentas capazes de veicular o conhecimento científico para um público leigo. Neste caso, essa veiculação pode ser realizada tanto por espaços formais quanto não formais de ensino como mídias impressas e televisivas, além de parques e museus (ALBAGLI, 1996; BUENO, 2010). Este recurso visa contribuir para uma alfabetização científica alinhada com os pressupostos apresentados por Sasseron e Carvalho (2008), que perpassa desde o entendimento de conceitos científicos básicos fundamentais, a compreensão de Natureza da Ciência até a sua relação com questões científicas e tecnológicas inseridas na sociedade. Porém, para que a DC seja compreendida pela população, é necessário que a DC passe por uma adaptação de discurso.

Neste sentido, Targino (2007) apresenta dois tipos de discurso: o científico e o jornalístico. Apesar da importância de ambos com o objetivo de aproximar o conhecimento científico da sociedade, eles diferem em alguns aspectos. O primeiro é fruto do conhecimento produzido no ambiente científico, da produção acadêmica como artigos e monografias. Ele expressa um caráter mais rigoroso e objetivo, com linguagem mais formal. O segundo é produzido por jornalistas e representa uma adaptação do discurso científico. O mesmo apresenta uma linguagem mais coloquial, tanto com "caráter informativo, via veiculação de notas, notícias, reportagens, entrevistas, etc., como caráter opinativo (editoriais, comentários, artigos, colunas, crônicas, cartuns e cartas)" (TARGINO, 2007, p.6).

Terrazzan e Gabana (2003) afirmam que os textos de divulgação científica (TDC) geralmente apresentam uma linguagem simplificada e compreensível para as pessoas, tratando o saber científico a partir do seu funcionamento, execução "ou ainda do estudo de fenômenos presentes no cotidiano das pessoas" podendo ser empregado em salas de aula (TERRAZZAN; GABANA, 2003, p.2). Além disso, os autores colocam que esse conhecimento é capaz de aproximar o leitor da prática científica, de modo que entenda a forma que a ciência é construída socialmente. 
Ensino, Saúde e Ambiente - V13 (1), pp. 1-19, Abr. 2020

\section{MUDANÇAS CLIMÁTICAS E OS TEXTOS DE DIVULGAÇÃO CIENTÍFICA}

As alterações climáticas no planeta são incontestáveis. De acordo com Leite (2015) a partir dos anos 1950, o aquecimento global antropogênico tornava-se cada vez mais evidente. Porém, é nos anos 1970 que a temática ganha mais notoriedade e em 1979, ocorre a Primeira Conferência Climática Mundial, em Genebra. A partir dessa década, a comunidade científica internacional tomou ciência dos acontecimentos relacionados à destruição da camada de ozônio e de suas consequências para o clima do planeta (CONTI, 2005).

Os principais efeitos destas alterações climáticas podem ser observados a partir do aquecimento global. Este processo é oriundo de alterações das dinâmicas naturais produzidas e intensificadas a partir do lançamento de gases na atmosfera (MENDONÇA, 2006). Com isso, consequências como: aumento da temperatura e dos níveis dos oceanos, perda da biodiversidade de diversas espécies marinhas e terrestres; são de fato observadas na atualidade (PEDRINI et al, 2016). No entanto, Conti (2005) ressalta que devem ser avaliadas as causas naturais e antrópicas relacionadas a esse processo e não restringir as mudanças climáticas a elevação da temperatura global e suas consequências, pois alterações do clima estão relacionadas ao dinamismo planetário influenciado por diversos fatores tanto a nível local e global.

Ao investigar o assunto mudanças climáticas em TDC, é possível verificar que esse tema tem sido abordado com certa recorrência nos estudos da área. Casagrande, Júnior e Mendonça (2011, p.13), durante sua análise em duas revistas de DC sobre a temática 'mudança climática', concluíram que o conteúdo não apresentava "uma postura consensual única e homogênea de instituições e cientistas". Em outro estudo sobre fenômenos climáticos, Xavier e Kerr (2004) observaram que os textos jornalísticos apresentavam de maneira inadequada a discussão a respeito do Efeito Estufa como agente principal das alterações do clima.

Com base na importância desempenhada pelos TDC e pelo fato das alterações climáticas serem consideradas uma temática relevante por suscitar questões acerca da relação homem-natureza, questiona-se de que forma as revistas Ciência Hoje e Superinteressante têm apresentado estes conteúdos.

Diante disto, o objetivo do estudo é investigar a abordagem dada, pelas revistas Ciência Hoje e Superinteressante, nos conteúdos referentes às mudanças climáticas durante o período de 2013 a 2016. 
Ensino, Saúde e Ambiente - V13 (1), pp. 1-19, Abr. 2020

\section{METODOLOGIA}

Este estudo caracteriza-se com uma pesquisa qualitativa, cujo referencial metodológico baseou-se na análise categorial temática (BARDIN, 1977). Como corpus de análise foram selecionadas as revistas Superinteressante e Ciência Hoje. A escolha das revistas se justifica pelo fato da Superinteressante ter a maior circulação entre as revistas de DC com publicação mensal no país (MENDES; BIZERRA, 2017). Já a revista Ciência Hoje, é ligada à Sociedade Brasileira para o Progresso da Ciência (SBPC) com sistema de arbitragem por pares, sendo o mesmo utilizado por revistas científicas o que reitera sua credibilidade e qualidade (LIMA, 1992).

Para a busca dos textos, utilizou-se as seguintes palavras-chave: 'aquecimento global', 'efeito estufa' e 'mudanças climáticas'. A revista Superinteressante, codificada como 'S', apresentou 12 textos (Quadro 1). Já a Ciência Hoje, codificada como 'CH', apresentou 18 textos (Quadro 2), totalizando 30 textos de divulgação científica.

O período analisado corresponde às edições dos anos de 2013 a 2016. Ressalta-se que o ano de 2017 não foi analisado, pois a revista Ciência Hoje não apresentou nenhuma versão impressa ou online de seu conteúdo.

\begin{tabular}{|c|c|l|c|c|l|}
\hline Código & Título & Autoria & Seção & Edição & Ano \\
\hline S01 & $\begin{array}{c}\text { Experiência para tentar } \\
\text { reverter o aquecimento } \\
\text { global pode resultar em } \\
\text { catástrofe }\end{array}$ & $\begin{array}{c}\text { Vinicius } \\
\text { Abbate }\end{array}$ & Ideias & Março & 2013 \\
\hline S02 & $\begin{array}{c}\text { Cientistas criam bactéria } \\
\text { que come CO } \text { C }_{2} \text { do ar }\end{array}$ & $\begin{array}{l}\text { Salvador } \\
\text { Nogueira }\end{array}$ & Ciência & Maio & 2013 \\
\hline S03 & $\begin{array}{c}\text { Efeito estufa afeta sexo } \\
\text { das Tartarugas }\end{array}$ & $\begin{array}{l}\text { Redação } \\
\text { (sem autor) }\end{array}$ & Saúde & Julho & 2013 \\
\hline S04 & $\begin{array}{c}\text { Ciência Maluca: Castor } \\
\text { tira CO2 da Atmosfera }\end{array}$ & $\begin{array}{l}\text { Carol Castro } \\
\text { aquecimento global }\end{array}$ & $\begin{array}{l}\text { Ciência } \\
\text { Nogueira }\end{array}$ & Setembro & 2013 \\
\hline S06 & $\begin{array}{c}\text { Aviões vão pegar mais } \\
\text { turbulência }\end{array}$ & $\begin{array}{l}\text { Redação } \\
\text { (sem autor) }\end{array}$ & Comportamento & Outubro & 2013 \\
\hline S07 & $\begin{array}{c}\text { Teremos cada vez mais } \\
\text { tornados }\end{array}$ & Carol Castro & Ideias & Novembro & 2013 \\
\hline S08 & Clima extremo & $\begin{array}{l}\text { Salvador } \\
\text { Nogueira }\end{array}$ & Comportamento & Março & 2014 \\
\hline S09 & $\begin{array}{c}\text { Brasil é o quarto maior } \\
\text { culpado pelo aquecimento }\end{array}$ & $\begin{array}{l}\text { Redação } \\
\text { (sem autor) }\end{array}$ & Ciência & Abril & 2014 \\
\hline
\end{tabular}


Ensino, Saúde e Ambiente - V13 (1), pp. 1-19, Abr. 2020

\begin{tabular}{|c|c|c|c|c|c|}
\hline & global & & & & \\
\hline S10 & $\begin{array}{l}\text { Superplanta faz mais } \\
\text { Fotossíntese }\end{array}$ & $\begin{array}{l}\text { Salvador } \\
\text { Nogueira }\end{array}$ & Ciência & Maio & 2014 \\
\hline S11 & $\begin{array}{l}\text { Aquecimento global afeta } \\
\text { a produtividade dos países }\end{array}$ & $\begin{array}{l}\text { Ana Luísa } \\
\text { Fernandes }\end{array}$ & Sociedade & Dezembro & 2015 \\
\hline $\mathrm{S} 12$ & $\begin{array}{l}\text { Café corre risco de } \\
\text { Extinção }\end{array}$ & $\begin{array}{l}\text { Ana Carolina } \\
\text { Leonardi }\end{array}$ & Sociedade & Outubro & 2016 \\
\hline
\end{tabular}

Quadro 1- Matérias selecionadas da revista Superinteressante com suas respectivas autoria, seção, edição e ano de publicação.

Fonte: Elaborado pelos autores.

\begin{tabular}{|c|c|c|c|c|c|}
\hline Código & Título & Autoria & Seção & Mês & Ano \\
\hline $\mathrm{CH} 01$ & Fé, ciência e a conta! & $\begin{array}{l}\text { Aliny P.F. Pires; } \\
\text { Viniciues F. } \\
\text { Farjalla }\end{array}$ & Ensaio & Maio & 2013 \\
\hline $\mathrm{CH} 02$ & $\begin{array}{l}\text { Por um futuro menos } \\
\text { incerto }\end{array}$ & Célio Yano & Climatologia & Junho & 2013 \\
\hline $\mathrm{CH} 03$ & Carbono carioca & $\begin{array}{l}\text { Redação (sem } \\
\text { autor) }\end{array}$ & Em dia & Agosto & 2013 \\
\hline $\mathrm{CH} 04$ & $\begin{array}{l}\text { Terra: uma história } \\
\text { climática }\end{array}$ & $\begin{array}{l}\text { Redação (sem } \\
\text { autor) }\end{array}$ & $\begin{array}{l}\text { Divulgação } \\
\text { científica }\end{array}$ & Setembro & 2013 \\
\hline $\mathrm{CH} 05$ & $\begin{array}{c}\text { Emissões na ponta do } \\
\text { lápis }\end{array}$ & $\begin{array}{l}\text { Redação (sem } \\
\text { autor) }\end{array}$ & Em dia & Jan/Fev & 2015 \\
\hline $\mathrm{CH} 06$ & A seca e o desmatamento & Philip M. Fearnside & Opinião & $\mathrm{Jan} / \mathrm{Fev}$ & 2015 \\
\hline $\mathrm{CH} 07$ & Gaseificação: o retorno & $\begin{array}{l}\text { Marco Tsuyama } \\
\text { Cardoso }\end{array}$ & Ensaio & Maio & 2015 \\
\hline $\mathrm{CH} 08$ & $\begin{array}{l}\text { Desafios impostos pelo } \\
\text { clima }\end{array}$ & Sérgio Magalhães & $\begin{array}{l}\text { Cidade } \\
\text { inteira }\end{array}$ & Agosto & 2015 \\
\hline $\mathrm{CH} 09$ & $\begin{array}{l}\text { Mudanças climáticas: } \\
\text { Emergência médica }\end{array}$ & $\begin{array}{l}\text { Redação (sem } \\
\text { autor) }\end{array}$ & $\begin{array}{l}\text { Mundo da } \\
\text { ciência }\end{array}$ & Agosto & 2015 \\
\hline $\mathrm{CH} 10$ & Vida em risco nos recifes & $\begin{array}{l}\text { Alicia Ivanissevich; } \\
\text { Iara Pinheiro }\end{array}$ & Pelo Brasil & Novembro & 2015 \\
\hline $\mathrm{CH} 11$ & $\begin{array}{l}\text { Participação dos povos da } \\
\text { floresta }\end{array}$ & $\begin{array}{l}\text { Redação (sem } \\
\text { autor) }\end{array}$ & Pelo Brasil & Jan/Fev & 2016 \\
\hline $\mathrm{CH} 12$ & $\begin{array}{c}\text { O 'clima' do Acordo de } \\
\text { Paris }\end{array}$ & Moema Correa & Opinião & $\mathrm{Jan} / \mathrm{Fev}$ & 2016 \\
\hline $\mathrm{CH} 13$ & $\begin{array}{c}\text { A destruição que ninguém } \\
\text { vê }\end{array}$ & $\begin{array}{l}\text { Erika Berenguer; } \\
\text { Joice Ferreira; } \\
\text { Toby Alan } \\
\text { Gardner; Jos } \\
\text { Barlow }\end{array}$ & Ecologia & Junho & 2016 \\
\hline
\end{tabular}


Ensino, Saúde e Ambiente - V13 (1), pp. 1-19, Abr. 2020

\begin{tabular}{|c|c|c|c|c|c|}
\hline CH14 & $\begin{array}{l}\text { Brasil reduz em mais de } \\
50 \% \text { emissão de gás } \\
\text { carbônico entre } 2005 \text { e } \\
2010\end{array}$ & $\begin{array}{l}\text { Redação (sem } \\
\text { autor) }\end{array}$ & $\begin{array}{c}\text { Informe } \\
\text { publicitário }\end{array}$ & Junho & 2016 \\
\hline $\mathrm{CH} 15$ & Ainda inconveniente & $\begin{array}{l}\text { Jean Remy } \\
\text { Guimarães }\end{array}$ & Crítica & Julho & 2016 \\
\hline CH16 & $\begin{array}{c}\text { Nova tecnologia } \\
\text { desenvolvida no Inpe } \\
\text { melhora estimativas sobre } \\
\text { queimadas }\end{array}$ & $\begin{array}{l}\text { Redação (sem } \\
\text { autor) }\end{array}$ & $\begin{array}{l}\text { Informe } \\
\text { publicitário }\end{array}$ & Agosto & 2016 \\
\hline $\mathrm{CH} 17$ & $\begin{array}{c}\text { Sentinela das mudanças } \\
\text { climáticas }\end{array}$ & $\begin{array}{c}\text { Wilson Fernandes; } \\
\text { Hernani A. } \\
\text { Almeida; Felipe } \\
\text { Melo; Cássio A. } \\
\text { Nunes; Frederico } \\
\text { Neves; Yule } \\
\text { Roberta F. Nunes; } \\
\text { Patricia Morellato; } \\
\text { Rodolfo Dirzo }\end{array}$ & Ecologia & Agosto & 2016 \\
\hline CH18 & $\begin{array}{l}\text { Como as espécies irão } \\
\text { reagir às mudanças } \\
\text { climáticas }\end{array}$ & $\begin{array}{c}\text { Leandra } \\
\text { Bordignon; Geraldo } \\
\text { Wilson Fernandes; } \\
\text { Yumi Oki; Ana } \\
\text { Paula de Faria }\end{array}$ & Biologia & Outubro & 2016 \\
\hline
\end{tabular}

Quadro 2- Matérias selecionadas da revista Ciência Hoje com suas respectivas autoria, edição e ano de publicação

Fonte: Elaborado pelos autores.

Os textos de DC foram analisados em relação à autoria; à seção onde estão situados; às imagens; à linguagem (presença de termos explicativos relacionados aos conceitos científicos e acessibilidade ao leitor) e quanto à precisão científica (existência ou não de erros conceituais). Vale lembrar que as imagens foram analisadas de acordo com as categorias definidas por Pralon (2015): fotografias, desenhos, gráficos e esquemas. A análise das funções das imagens no texto se deu a partir do estudo de Martins; Cassab e Rocha (2001), sendo essas: destaque, motivação, informação, exemplificação e explicação.

\section{RESULTADOS E DISCUSSÃO}

Dos trinta textos analisados, dez foram produzidos pela redação das revistas, isto é, não há autores citados como responsáveis pela produção do artigo. São eles: S03, S06, S09, $\mathrm{CH} 3, \mathrm{CH} 4, \mathrm{CH} 5, \mathrm{CH} 9, \mathrm{CH} 11, \mathrm{CH} 14$ e $\mathrm{CH} 16$. Dos artigos com autores identificados, na revista Superinteressante todos são jornalistas. Não há participação de especialistas na autoria 
dos textos. Sendo jornalistas, a possibilidade de publicação dos textos de DC nas diversas seções da revista (como veremos adiante) aumenta, já que, o jornalista ou divulgador trabalha com a decodificação (ou até mesmo recodificação) do texto/linguagem especializada seja ele qual for.

Além de todos serem jornalistas, todos os artigos foram escritos por apenas um autor. Reiteramos o que Bueno (2010) reconhece como fundamental que a decodificação do discurso especializado abre espaço para incompreensão entre jornalistas e a fonte porque cada parte está inserida numa cultura profissional distinta, que contempla a Ciência e a Tecnologia de forma diversa.

Dos textos analisados na revista Ciência Hoje onde o autor é registrado, somente dois ( $\mathrm{CH} 2$ e CH10) são produzidos por jornalistas. Os demais foram escritos por especialistas de diversas áreas, de diferentes instituições de ensino e pesquisa, de órgãos públicos e privados. Analisando que tipo de autor produziu os textos, é possível perceber que essa revista oferece espaço de publicação para especialistas e jornalistas (não especialistas). Vale ressaltar que em alguns artigos há vários autores, diferenciando-se dos artigos da revista Superinteressante que por sua vez, adota a política de apenas um autor para cada artigo.

Portanto, nove matérias foram publicadas por especialistas, sete foram publicados pela redação, e apenas dois foram publicados por jornalistas. Esses dados corroboram com Casagrande, Junior e Mendonça (2011), quando sinalizam que a revista Ciência Hoje publica as principais matérias com autores cientistas, o que lhe confere um "prestígio típico" perante o público leitor.

A presença de jornalistas como autores de artigos nas duas revistas evidencia a importância de investigar como o jornalismo científico tem se comportado nos veículos de DC, sobretudo, nas revistas. Castelfranchi (2008) coloca o jornalismo científico como responsável por comunicar a ciência de forma contextualizada, crítica e rigorosa. Ele coloca então um caráter social, pois para isso, é preciso reconhecer os efeitos culturais que essa comunicação provoca. Elementos do jornalismo serviriam, então, para construir um texto de DC com maior potencial de compreensibilidade. Entretanto, Bueno (2010) sinaliza que na construção do texto, o jornalista pode privilegiar, por diversos motivos, a espetacularização da notícia deixando de lado a precisão ou completude da informação em detrimento da ampliação da audiência.

Existe, segundo Alferes (2008), a necessidade discursiva de produzir o efeito de estar divulgando resultados científicos na DC. Isso afeta o processo de "sutura" entre os discursos. E nesse contexto, especialistas e jornalistas são afetados de igual modo, cada um em sua área profissional. 
Ensino, Saúde e Ambiente - V13 (1), pp. 1-19, Abr. 2020

Em relação à seção em que aparecem os textos sobre mudanças climáticas, observouse que na Ciência Hoje, as seções "Ecologia", "Em dia", "Opinião" e "Pelo Brasil" apresentaram duas publicações cada. Os demais textos encontraram-se distribuídos em outras seções, cada uma com um artigo. Desse modo, infere-se que a questão das mudanças climáticas tem sido abordada pela revista nas mais diversas seções pelo fato de ser uma temática que dialoga com diferentes áreas do conhecimento.

A revista Superinteressante também publicou os artigos organizados por seção, porém as mesmas são intituladas de forma diferente em relação à revista anterior. A seção que obteve maior número de publicação (quatro) foi "Ciência", seguida de três publicações na seção "Ideias", duas publicações na seção "Comportamento e Sociedade" e uma publicação na seção Saúde. Percebeu-se aqui que a revista aloca a maioria dos artigos sobre mudanças climáticas na seção mais direcionada para o conhecimento científico.

Em relação às imagens, na Ciência Hoje apenas $\mathrm{CH04}$ e CH08 não apresentaram ilustrações. O recurso imagético mais utilizado, assim como observado na revista Superinteressante, foram as fotografias, presentes nos dezesseis textos com imagens. De acordo com Martins, Cassab e Rocha (2001), as imagens, de um modo geral, são capazes de auxiliar na compreensão de textos científicos, direcionando o entendimento daquele saber e tornando o conteúdo mais claro. Em relação à presença de legenda, nove textos $(\mathrm{CH} 01$, CH03, CH05, CH06, CH07, CH09, CH10, CH14 e CH16) não possuíram nenhum tipo de acompanhamento deste recurso, quatro (CH02, CH11, CH12 e CH13) apresentaram legenda em todas as imagens e três ( $\mathrm{CH} 15, \mathrm{CH} 17$ e $\mathrm{CH} 18)$, por apresentarem mais de uma imagem no conteúdo, apenas algumas figuras eram acompanhadas do recurso verbal.

Os textos $\mathrm{CH} 02, \mathrm{CH} 13, \mathrm{CH} 15, \mathrm{CH} 17$ e $\mathrm{CH} 18$ apresentaram mais de uma imagem, onde, além de apenas fotografias (como observado em CH15 e CH18) continham também gráficos (CH13), mapas (CH02 e $\mathrm{CH} 17)$ e desenhos com esquemas (CH17), todas com o objetivo de levar dados e informar o leitor sobre determinados elementos relacionados ao tema. Desta forma, apresentaram uma função informativa (Figura 1). Além disso, pelo fato destes textos possuírem mais de uma ilustração, estes apresentaram mais de uma função, como a ilustrativa (CH01, CH03, $\mathrm{CH} 05, \mathrm{CH} 06, \mathrm{CH} 09, \mathrm{CH} 10, \mathrm{CH} 12, \mathrm{CH} 15, \mathrm{CH} 17$ e CH18) e a de exemplificação (CH02, CH07, CH11, CH13, CH14, CH15, CH16 e CH18). 
Ensino, Saúde e Ambiente - V13 (1), pp. 1-19, Abr. 2020

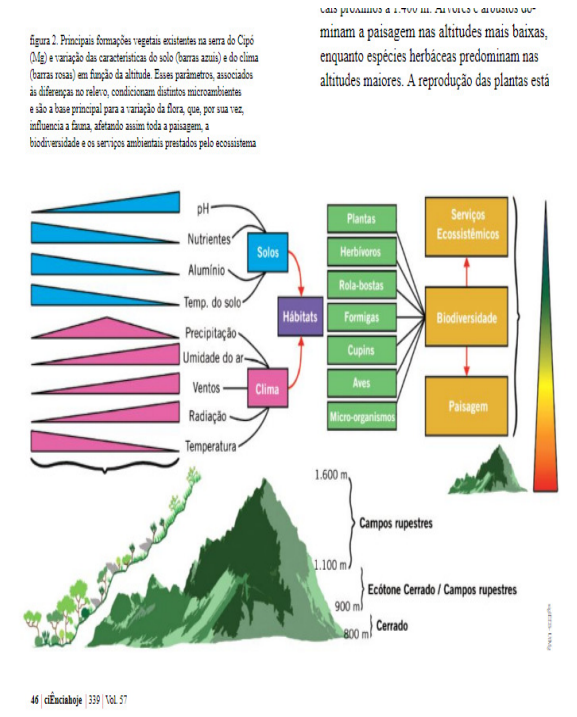

Figura 1- Figura retirada de $\mathrm{CH} 17$, de caráter informativo.

Fonte: Revista Ciência Hoje, n.339, p.46, 2016.

Dos doze textos encontrados na revista Superinteressante, apenas S01, S03 e S04 não apresentaram recursos imagéticos. As figuras encontradas nos demais textos representavam fotografias, com exceção de S08 que apresentou somente gráfico e S09, que apresentou tanto fotografia quanto gráfico. Vale ressaltar que as fotografias possuem um alto grau de iconicidade, ou seja, elas representam o elemento de forma semelhante à realidade (SEBATA; SANTOS; CARNEIRO, 2005) e por este fato, acredita-se esse tipo de imagem é mais utilizado do que desenhos, gráficos e esquemas, que possuem um grau iconicidade menor. Ainda em relação à $\mathrm{S} 09$, este texto foi o único que apresentou mais de uma imagem e o único a apresentar uma legenda em um dos dois recursos imagéticos encontrados. Vale lembrar que algumas imagens necessitam estar acompanhadas de um texto para que sejam compreendidas, onde um elemento complementa o outro (CALADO, 1994). No caso de S08, a ausência deste recurso dificultou a compreensão do gráfico apresentado.

Em relação às funções desempenhadas pelas figuras, S02, S05, S07, S08 e S10 foram consideradas exemplificações do conteúdo abordado no texto. Já S06, S09, S11 e S12 apresentaram um caráter ilustrativo (Figura 2). 

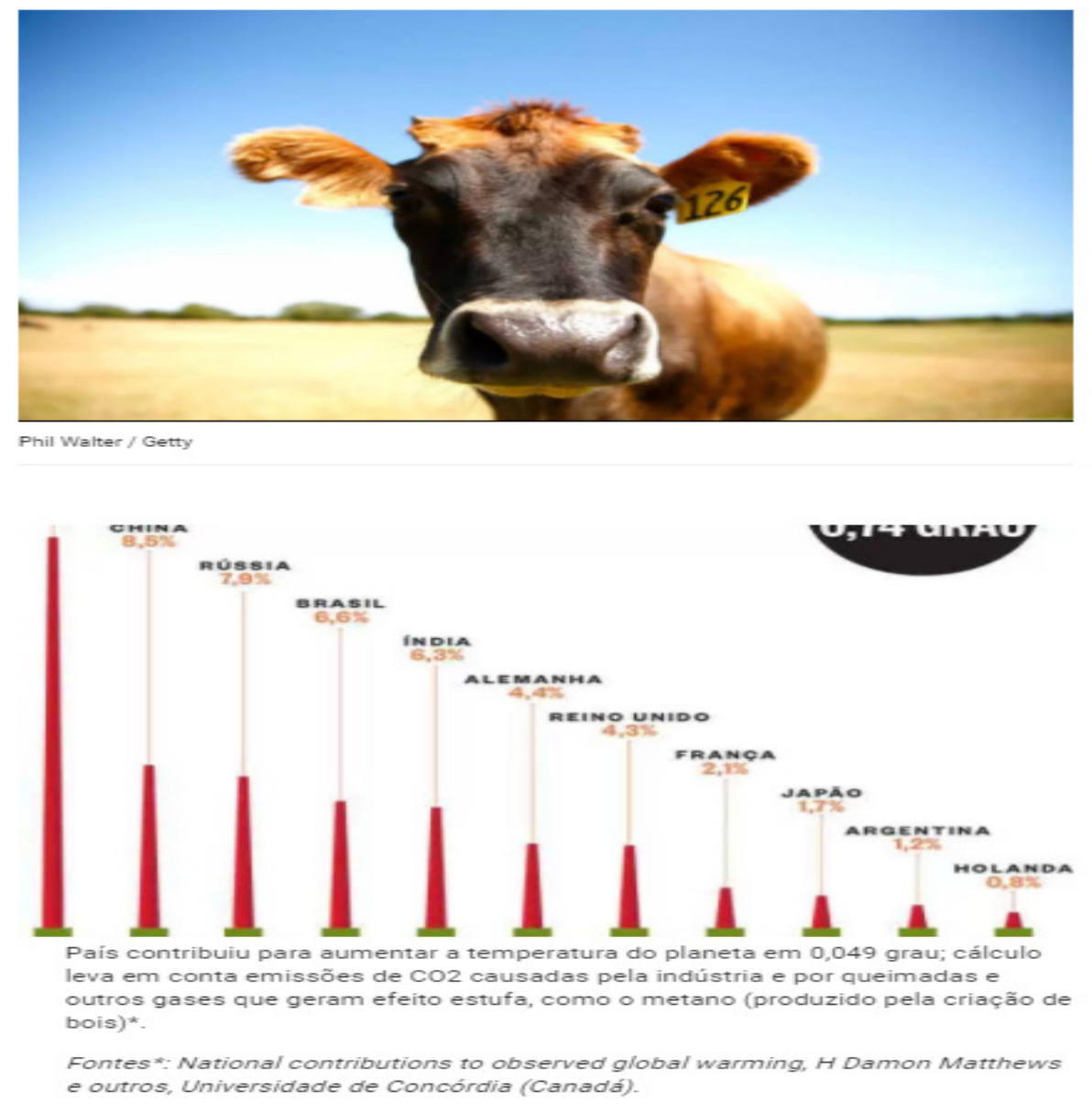

Figura 2- Imagens presentes em S09.

Fonte: Revista Superinteressante, Abril, 2014.

No que diz respeito à linguagem, dos dezoito artigos encontrados na Ciência Hoje, dezessete foram classificados como de linguagem acessível e de fácil compreensão ao leitor. A exemplo disto destaca-se nos artigos $\mathrm{CH03,} \mathrm{CH04,} \mathrm{CH06}$ e $\mathrm{CH} 09$ a presença de expressões de cunho informal, como as extraídas do $\mathrm{CH} 09$ (p. 15): “empurrando com a barriga" $e$ "botar a perder". Com isso, o uso de expressões com linguagem coloquial e o uso de verbos conjugados na primeira pessoa do plural como "nós" e "temos", indicam a tentativa de tornar a abordagem do conhecimento mais próxima da realidade do leitor, de modo a usar destes recursos para incluí-lo no problema apresentado. Somente um artigo (CH18) apresentou linguagem mais rebuscada devido à utilização de termos próprios da ciência que não são explicados ao longo do texto, condicionando a compreensão do mesmo ao conhecimento prévio do leitor.

Ainda com relação à linguagem, o primeiro item que foi analisado se relaciona com a presença dos termos ou conceitos científicos junto a definições sobre os mesmos. Inicialmente, é preciso ressaltar que não se obteve o mesmo resultado em todas as reportagens, pois mesmo as matérias que discorriam sobre determinado conceito não apresentavam o detalhamento de outro conceito considerado como relevante para a 
compreensão do assunto abordado. Logo, divide-se o resultado em quatro possibilidades: apresentação de definição para todos os termos considerados relevantes no texto, ausência de termos explicativos mesmo com a existência de conceitos relevantes, definição de alguns termos explicativos e outros que não são detalhados e ausência de qualquer conceito científico. Portanto, segundo as classificações acima, sete reportagens estavam relacionadas à primeira possibilidade $(\mathrm{CH} 1, \mathrm{CH} 11, \mathrm{CH} 12, \mathrm{CH} 13, \mathrm{CH} 14, \mathrm{CH} 16, \mathrm{CH} 18)$, quatro matérias enquadraram-se na segunda ( $\mathrm{CH03}, \mathrm{CH05}, \mathrm{CH} 09, \mathrm{CH} 10)$, seis apresentaram o detalhamento de alguns termos e outros não ( $\mathrm{CH06}, \mathrm{CH07,} \mathrm{CH} 15, \mathrm{CH} 17)$ e apenas um, o $\mathrm{CH08,} \mathrm{não}$ apresentou nenhum termo específico.

A título de exemplificação, destaca-se o $\mathrm{CH} 17$, pois este aborda uma gama de conceitos, mas não fornece definição ou maior detalhamento para termos como: insetos herbívoros, atividades antrópicas, espécies, ecossistemas, fauna e flora. Por outro lado, o autor define de forma simples e direta conceitos como: campos rupestres, forrageamento e espécies endêmicas. Esta última pode ser observada na seguinte frase $(\mathrm{CH} 17, \mathrm{p} .43)$ : “... além de várias espécies endêmicas (encontradas somente nesses ambientes)”.

Além disso, destaca-se como relevante a definição de siglas relacionadas a importantes entidades científicas e eventos relacionados com o tema 'mudanças climáticas', como por exemplo, a IPCC e COP21. Estas siglas foram encontradas nos textos CH01, CH02, CH11, CH12, CH15 e no fragmento de CH18 (p.27): "Segundo o Painel Intergovernamental de Mudanças do Clima (IPCC), na sigla em inglês."

Foram encontradas quatro figuras de linguagem em alguns dos dezoito textos analisados, tais como metáfora, personificação, metonímia e analogia. A metáfora consiste na utilização de uma palavra em sentido diferente do habitualmente utilizado por relação de semelhança entre as mesmas, estabelecendo uma comparação implícita nas ideias apresentadas (KEMPER; ZIMMERMANN; GASTAL, 2010). Elas foram encontradas nos textos $\mathrm{CH05}$ e CH17 em diferentes localizações do texto. Em CH05, a metáfora está presente exclusivamente no título do texto, a partir da expressão “Emissões na ponta do lápis” ao fazer referência de forma indireta a uma nova metodologia de medição da emissão dos gases do efeito estufa disponível para o setor da agropecuária. Já em $\mathrm{CH} 17$, a figura de linguagem é encontrada no corpo do texto de maneira a associar as montanhas a laboratórios naturais, como pode ser observado no fragmento a seguir $(\mathrm{CH} 17, \mathrm{p} .43)$ : “As montanhas representam um grande repositório de vida silvestre e são laboratórios naturais, pois funcionam como verdadeiros medidores de efeitos das alterações climáticas sobre os seres vivos.”

Quanto à personificação, esta figura de linguagem foi encontrada em CH13 e CH17. Segundo Caron e Rigonato (2013, p.14) a personificação "consiste em 
contextualizar/categorizar entidades ou fenômenos não-humanos em termos humanos, atribuindo características próprias de uma pessoa a um determinado fenômeno alvo." No texto de $\mathrm{CH} 13$, é associada uma característica humana a base das árvores, como destacado no trecho a seguir do texto (CH13, p.28): “assim como queima o pé das árvores ali presentes." No CH17 associa-se 'montanhas' a 'sentinelas' de modo que as montanhas assumem a característica de emitir alertas provenientes de sentinelas, como destacado a seguir ( $\mathrm{CH} 17$, p.47): “As montanhas assumem o papel de sentinela ao nos alertar para os impactos que as mudanças no clima poderão ter sobre a biodiversidade.."

A figura de linguagem denominada metonímia é compreendida na língua portuguesa como a substituição de um termo pelo outro através da relação de significados. É possível verificar essa figura em um fragmento de $\mathrm{CH11(p.47):} \mathrm{“a} \mathrm{ideia} \mathrm{é} \mathrm{mudar} \mathrm{o} \mathrm{paradigma} \mathrm{de}$ desenvolvimento associado a desmatamento para um modelo em que se valorize a floresta em pé.”. Em CH13 (p.27), este recurso está presente na seguinte expressão: “Já a degradação se refere ao processo em que a floresta continua em pé." Ao analisar os fragmentos apresentados anteriormente, detectou-se relação de proximidade entre essa representação e a personificação, pois se utilizou características humanas associadas às árvores. No entanto, foi atribuído ao termo "em pé" o sentido de resistência, principalmente no que diz respeito ao desmatamento, onde mesmo com todas as mudanças que ocorrem no planeta, ainda existam árvores intactas.

Por último, observou-se a presença de analogia, que é semelhante à comparação. Porém, segundo Rigolon e Obara (2010), as duas se diferenciam em relação aos domínios de conhecimento, não apresentando, portanto, semelhanças totais ou parciais.

Com base nesta definição, foi detectada analogia apenas no CH09 ao destacar a necessidade de atenção política para mudanças de atitude a nível global devido às implicações das alterações climáticas na saúde global. Portanto, associa-se a vontade política de mudança a uma nuvem no horizonte, ou seja, a esperança para a sociedade; como pode ser observado neste fragmento (CH09, p.15): "Mas, claro, há só aquela pequena nuvem no horizonte: a “vontade política global."

Além disso, foi encontrada nos textos analisados a presença de ambiguidade de sentido no título de $\mathrm{CH} 12$ e CH03. Em CH12 o título “O 'clima' do acordo de Paris” aborda o acordo de Paris, de modo a debater as causas e consequências em relação a alta incidência de emissão de gases poluentes. Logo, a ambiguidade no título justifica-se devido à abordagem das mudanças climáticas como temática central e a possibilidade de opiniões divergentes em relação às atitudes a serem tomadas para a redução da emissão dos gases ocasionando um conflito de ideias durante o encontro. Quanto a CH03, o texto intitulado "Carbono carioca" 
ressalta a associação entre as emissões de gases poluentes com compostos de carbono em sua composição com o estado do Rio de Janeiro. Com isso, o leitor ao se apropriar do texto detecta esta associação através do destaque fornecido ao Rio de Janeiro, pois é o primeiro a realizar um cálculo de estimativas em relação às emissões de gases poluentes para o planeta.

$\mathrm{Na}$ análise dos doze artigos da revista Superinterressante todos foram classificados como de linguagem informal, sendo este resultado comparável com o estudo realizado por Kemper, Zimmermann e Gastal (2010). Os autores identificaram, através da análise comparativa entre as revistas Superinteressante e Galileu, que a primeira apresenta linguagem informal, indicando esta característica como um artifício de aproximação do público e estimulando a criação de um sentimento de identidade entre o leitor e a revista. Além disso, destaca-se nesses textos o caráter informativo fornecido através da simplicidade da linguagem ao aproximar as informações científicas do público alvo.

A característica informativa dos textos da Superinterressante está relacionada ao uso de termos explicativos de alguns conceitos básicos, como pode ser observado nos textos S01, S02, S05, S07 e S10. A título de ilustração, destaca-se o fragmento extraído do texto S10 (s/n): “... nos cloroplastos - as estruturas da planta que fazem a fotossíntese.”. Ferreira e Queiroz (2011) afirmam que o uso do recurso de definição de termos científicos torna-se relevante para diminuir o distanciamento do leitor em relação ao assunto abordado, através da atenuação de termos técnicos e científicos.

Em relação às figuras de linguagem, foram encontradas apenas metáfora e analogia nos textos analisados. A primeira foi encontrada em S08 e S11, referindo-se, respectivamente, a intensidade do sol e a relação do aquecimento global com a produtividade, conforme pode ser observado nos fragmentos a seguir: S08 (s/n): “coincidiu com a baixa frequência de manchas solares. Ou seja, o calorão está de rachar mesmo com o Sol dando uma trégua". $\mathrm{S} 11(\mathrm{~s} / \mathrm{n})$ "Não é só o planeta que sofre com as consequências do aquecimento global: a sua carteira pode estar mais vazia por causa dele".

Quanto à analogia, este recurso foi encontrado apenas em dois (S01, S07) dos doze textos analisados. No texto S01, ela está relacionada ao processo de fotossíntese, pois ao citar que durante o referido processo as plantas se alimentam de gás carbônico e luz ao invés de utilizarem esses reagentes no processo. Logo, a utilização da palavra "alimentam" fornece ao leitor o sentido da fotossíntese como um processo mecânico controlado pelo ser vivo que o realiza, ocasionando a compreensão incorreta do conceito. Zambon e Terrazzan (2007) ressaltam o alto potencial pedagógico do uso de analogias, entretanto, afirmam que é necessário cuidado e atenção no uso deste recurso linguístico em TDC, pois o excesso de simplificações poderá ocasionar a compreensão incorreta do conceito abordado. Além do 
Ensino, Saúde e Ambiente - V13 (1), pp. 1-19, Abr. 2020

fragmento do texto S01, foram extraídos do texto S07 outros exemplos de analogia. No fragmento S07 (s/n) a gíria "crias" se refere aos itens oriundos do aquecimento global, ou seja, produtos desse processo: "Nesses dias mais quentes, a umidade e o vento, as duas crias do aquecimento global, se juntam e causam as grandes tempestades.”

No que tange erros conceituais e explicações imprecisas, a revista Superinteressante apresentou quatro textos com imprecisão científica (S01, S02, S07 e S10), já a revista Ciência Hoje apresentou um texto com erro, o $\mathrm{CH} 18$. Diante do total de textos analisados, a Superinteressante mostra um percentual de $33 \%$ de seus artigos contendo erros. Vale ressaltar que os erros conceituais observados nos textos de DC podem se tornar um importante recurso didático quando favorece ao estudante a leitura de forma crítica entendendo a dificuldade de transmitir conhecimentos científicos para um público leigo, como apontam Kemper, Zimmermann e Gastal (2010).

Em relação à Ciência Hoje, o único erro encontrado foi no texto $\mathrm{CH} 18$ está relacionado à escrita científica. $\mathrm{O}$ nome científico segue algumas regras que devem ser observadas para fim de padronização. A revista não seguiu as regras ao citar o nome científico da planta Alecrim-do-campo na legenda de uma figura. Entretanto, este erro observado pode estar relacionado aos problemas de formatação do texto, já que esta revista foi analisada com base na versão online.

No texto S01 da Superinteressante, o autor comete algumas simplificações exageradas o que, em conjunto com o uso de analogia, causaram erros conceituais. Ele coloca que as plantas e algas que realizam fotossíntese "se alimentam de $\mathrm{CO}_{2}$ e luz". Luz e dióxido de carbono $\left(\mathrm{CO}_{2}\right)$ são elementos essenciais no processo de fotossíntese, mas não são alimentos. Outro equívoco é encontrado quando o autor afirma que o ferro é adorado pelas algas porque é "necessário para a fotossíntese". Na verdade, elas conseguem realizar fotossíntese sem a presença de ferro. O ferro seria importante para acelerar o processo de proliferação do fitoplâncton. Por último, o autor coloca: "fitoplâncton, um conjunto de plantas e algas que vivem no mar e faz fotossíntese, ou seja, se alimenta de $\mathrm{CO}_{2}$ e luz.". Erroneamente acrescenta as plantas nesse conjunto.

Ao explicar o processo de absorção de dióxido de carbono pelos organismos citados em seu texto, o autor do texto S02 utiliza termos populares que não traduzem o real processo biológico, “... uma criatura capaz de algo muito útil: alimentar-se de $\mathrm{CO}_{2}$ ”. Na verdade o gás carbônico $\left(\mathrm{CO}_{2}\right)$ não constitui alimento para a bactéria. Ela absorve o gás no processo. Em outro momento, isso se repete: "Depois de comer o gás, ele excreta ácido 3hidroxipropiônico...”. 
Analisando o texto S07, há um trecho em que a autora faz uma explicação pouco fundamentada cientificamente: "Isso porque o aumento da temperatura fornece o principal combustível das tempestades fortes: a energia potencial convectiva disponível (CAPE)". Ela coloca a energia citada como principal combustível. Na realidade existem outros fatores tão importantes quanto a CAPE. Além disso, ela não explica o que é essa energia. Apenas estabelece uma relação entre o aquecimento global e o cisalhamento fazendo aumentar a CAPE. Sendo assim, faltou precisão científica na contextualização e na busca por estabelecer uma relação. Talvez porque a CAPE não seja tão simples de explicar sendo oriunda da Meteorologia Aplicada.

$\mathrm{O}$ artigo S10 que traz em seu título "Superplanta faz mais fotossíntese" não mencionou a água como componente essencial para a realização da fotossíntese. Cita outros componentes, mas ausenta o componente "água" do processo, o que configura um erro importante visto que o texto possui um caráter predominantemente explicativo.

A presença ou não de erros conceituais pode indicar o rigor com que cada revista apresenta seus temas. Bueno (2010) aponta que a mediação entre a fonte de informação (cientista, pesquisador, universidade, centro de pesquisa, institutos, etc.) e o divulgador pode elevar o nível de ruídos na interação com o público não especializado, comprometendo possivelmente a qualidade da informação. Nesse contexto, os erros conceituais podem surgir nessa procura pela mediação adequada. No caso da revista Superinteressante, os erros conceituais podem ser pelo fato da não especialidade dos autores (todos são jornalistas) e também da participação dos redatores (todos jornalistas). Isso não significa que a revista não cumpra seu papel de divulgadora do conhecimento científico, mas, certamente sua credibilidade junto às fontes primárias das informações fica comprometida.

\section{CONCLUSÃO}

Em relação às imagens, notou-se que a revista Ciência Hoje apresentou um maior número de figuras do que a Superinteressante. O recurso imagético que foi mais utilizado em ambas as revistas de divulgação científica foram as fotografias. Acredita-se que ela tenha sido mais utilizada pelo seu baixo grau de abstração e por retratar de forma clara os assuntos cotidianos. De modo geral, estas ilustrações, estavam, em sua maioria, sem legenda e foram consideradas ilustrativas por apenas ilustrarem o que estava sendo retratado nos textos, sem acrescentar novas informações.

A análise do critério 'linguagem' possibilitou relacionar as revistas analisadas através de semelhanças e diferenças nos resultados obtidos. A semelhança se relaciona com os recursos literários apresentados, como as figuras de linguagem e alta incidência de termos 
explicativos. Os recursos literários citados anteriormente são frequentemente utilizados em textos de divulgação científica, pois são utilizados como estratégias de envolvimento do leitor no tema, de forma a aproximá-lo de conteúdos científicos de forma didática. No entanto, ao se relacionar quantitativamente a presença destes recursos são identificadas as diferenças entre as revistas.

As revistas comportaram-se de forma semelhante em relação a quantidade do uso de figuras de linguagem e estratégias de analogia. Contudo, a revista Ciência Hoje apresentou a personificação e metonímia em alguns dos textos analisados. Logo, este resultado indica que maiores estratégias de envolvimento do leitor estão presentes nesta revista.

Outro importante aspecto a ser ressaltado, está relacionado a presença de termos explicativos de conceitos científicos presente nos textos. Ao analisar comparativamente, identificou-se que na revista Ciência Hoje foram identificadas de forma mais marcante as definições sobre os termos científicos, enquanto, na revista Superinterresante foram encontrados em um quantitativo menor. O resultado obtido possivelmente esta relacionado a redação das duas revistas, pois na primeira os redatores são especialistas da área, logo estão aptos a julgar e a definir quais os termos explicativos são essenciais para a ampla compreensão do tema. Enquanto, na segunda revista, os redatores são oriundos da área da Comunicação, dificultando tanto a definição correta e adequada dos termos quanto o julgamento da essencialidade da presença de um termo em detrimento de outro.

A não observância de erros conceituais, salvo o erro de escrita científica observada na legenda da foto mencionado anteriormente, na revista Ciência Hoje traz uma maior credibilidade entre as revistas de DC, bem como, às fontes primárias do conhecimento científico. A presença de autores especialistas (pesquisadores, cientistas, acadêmicos) é um forte indicador da falta de erros conceituais. A presença de erros conceituais em textos da revista Superinteressante pode ser atribuída, também, pelos textos escritos por um autor apenas, somado ao fato de todos serem jornalistas (não especialistas).

Desta forma, apesar das diferenças observadas nas duas revistas de divulgação científica, os textos exploram de forma compreensiva os conteúdos, apresentando recursos linguísticos e imagéticos semelhantes. Conclui-se, portanto, que as revistas analisadas deram certo destaque ao tema mudanças climáticas em suas edições e que se constituem como potenciais recursos para a divulgação das questões ambientais para o público em geral.

\section{AGRADECIMENTO}

Coordenação de Aperfeiçoamento de Pessoal de Nível Superior (CAPES). 
Ensino, Saúde e Ambiente - V13 (1), pp. 1-19, Abr. 2020

\section{REFERÊNCIAS BIBLIOGRÁFICAS}

ALBAGLI, S. Divulgação científica: Informação científica para a cidadania?.Ciência da Informação, Brasília, v. 25, n. 3, p. 396-404, 1996. Disponível em:< http://revista.ibict.br/ciinf/article/view/639/643 > Acesso em 20 de outubro de 2017.

ALFERES, S. C. A escrita da divulgação científica. Horizonte Científico, v. 2, n. 1, 2008. Disponível em:<

www.seer.ufu.br/index.php/horizontecientifico/article/download/4134/3081> Acesso em 01 de novembro de 2017.

BARDIN, L. Análise de conteúdo. $3^{\text {a }}$ ed. Lisboa: Edições 70, 1977.

BUENO, W. C. Comunicação científica e divulgação científica: aproximações e rupturas conceituais. Informação \& Informação, Londrina, v. 15, n. esp, p. 1-12, 2010. Disponível em:< http://www.uel.br/revistas/uel/index.php/informacao/article/viewFile/6585/6761> Acesso em 29 de novembro de 2017.

CALADO, I. A utilização educativa das imagens. Portugal: Editora Porto, p.1-128, 1994.

CARON, M. F.; RIGONATO, M. B. Metáforas da "Terra da Gente" e a aprendizagem midiática de conceitos científicos. Ciência e Cognição, v.18, n.1, p. 2- 19, 2013. Disponível em: $<$ http://www.cienciasecognicao.org/revista/index.php/cec/article/view/824/pdf $>$ Acesso em 23 de novembro de 2017.

CASAGRANDE, A; JÚNIOR, P. S; MENDONÇA, F. mudanças climáticas e aquecimento global: controvérsias, incertezas e a divulgação científica. Revista Brasileira de Climatologia, v.8, p.30-44, 2011. Disponível em:< http://revistas.ufpr.br/revistaabclima/article/view/25793> Acesso em 02 de novembro de 2017.

CASTELFRANCHI, Y. Para além da tradução: o jornalismo científico crítico na teoria e na prática. In: Los desafíos y la evaluación del periodismo cientifico em Iberomerica. Jornadas Iberoamericanas sobre la ciência em los médios massivos. Editado por L. Massarani e C. Polino (AECI, RICYT, CYTED, SciDevNet, Santa Cruz de la Sierra, 2008). Disponível em < www.oei.es/historico/salactsi/libro_periodismo_cientifico.pdf $>$ Acesso em 10 de novembro de 2017.

CONTI, J.B. Considerações sobre as mudanças climáticas globais. Revista do Departamento de Geografia, v.16, p. 70-75, 2005. Disponível em:<

www.revistas.usp.br/rdg/article/view/47286> Acesso em 03 de novembro de 2017.

FERREIRA, L. N. de. A.; QUEIROZ, S. L. Artigos da revista Ciência Hoje como recurso didático no ensino de química. Química Nova, v.34, n.2, p.354-360, 2011. Disponível em:< http://www.scielo.br/scielo.php?pid=S010040422011000200033\&script=sci_abstract\&tlng=p > Acesso em 02 de dezembro de 2017.

KEMPER, A.; ZIMMERMANN, E.; GASTAL, M. L. Textos populares de divulgação científica como ferramenta didático pedagógica: o caso da evolução biológica. Revista Brasileira de Pesquisa em Educação em Ciências, São Paulo, v. 10, n. 3, p. 25-50, 2010. Disponível em:< https://seer.ufmg.br/index.php/rbpec/article/view/2288 > Acesso em 06 de dezembro de 2017.

LEITE, J. C. Controvérsias na climatologia: o IPCC e o aquecimento global antropogênico.

Scientiae Studia, São Paulo, v. 13, n. 3, p. 643-77, 2015. Disponível em:< http://www.scielo.br/pdf/ss/v13n3/2316-8994-ss-13-03-00643.pdf> Acesso em 02 de novembro de 2017. 
LIMA, M. Ciência Hoje nas bancas. Dissertação (Mestrado). Programa de Pós-Graduação em Comunicação Social, Instituto Metodista de Ensino Superior, São Bernardo do Campo, 1992.

MARTINS, I; CASSAB, M; ROCHA, M.B. Análise do processo de re-elaboração discursiva de um texto de divulgação científica para um texto didático. Revista Brasileira de Pesquisa em Educação em Ciências, v. 1, n. 3, p.1-9, 2001. Disponível em:<

http://www.cienciamao.usp.br/dados/rab/_analisedoprocessodere-el.artigocompleto.pdf $>$ Acesso em 20 de novembro de 2017.

MENDES, J. W. W; BIZERRA, A. F. A biologia na mídia: uma análise da revista Superinteressante. In: XI Encontro Nacional de Pesquisa em Educação em Ciências - XI ENPEC Universidade Federal de Santa Catarina, Florianópolis, SC - 3 a 6 de julho de 2017. Disponível em:< http://www.abrapecnet.org.br/enpec/xi-enpec/anais/resumos/R0422-1.pdf> Acesso em 16 de novembro de 2017.

MENDONÇA, F. Aquecimento global e suas manifestações regionais e locais: Alguns indicadores da região Sul do Brasil. Revista Brasileira de Climatologia, v.2, p.71-86, 2006. Disponível em: $<$ http://revistas.ufpr.br/revistaabclima/article/view/25388/17013 > Acesso em 02 de novembro de 2017.

PEDRINI, A. G; BROTTO, D. S; SANTOS, T. V; LIMA, L; NUNES, R. M. Percepção ambiental sobre as mudanças climáticas globais numa praça pública na cidade do Rio de Janeiro (RJ, Brasil). Ciênc. Educ., Bauru, v. 22, n. 4, p. 1027-1044, 2016. Disponível em:< http://www.scielo.br/pdf/ciedu/v22n4/1516-7313-ciedu-22-04-1027.pdf $>$ Acesso em 03 de novembro de 2017.

PRALON, L.H. Os livros didáticos de ciências dos anos iniciais e sua visualidade: primeiras observações. In: X Encontro Nacional de Pesquisa em Educação em Ciências. Anais...Águas de Lindóia, 2015. Disponível em:< http://www.abrapecnet.org.br/enpec/xenpec/anais2015/resumos/R0742-1.PDF> Acesso em 21 de novembro de 2017.

RIGOLON, R. F.; OBARA, A. T. Analogias na Ciência e no ensino de Ciências. In: SIMPÓSIO NACIONAL DE ENSINO DE CIÊNCIA E TECNOLOGIA, 3, 2010, Paraná. Anais...Paraná: 2010. Disponível em:< https://www.researchgate.net/publication/268511952_Analogias_na_Ciencia_e_no_ensino_de _Ciencia > Acesso em 23 de novembro de 2017.

SASSERON, L. H; CARVALHO, A. M. P. Almejando a alfabetização científica no ensino fundamental: A proposição e a procura de indicadores do processo. Investigações em Ensino de Ciências, v.13, n. 3, p.333-352, 2008. Disponível em:

$<$ https://www.if.ufrgs.br/cref/ojs/index.php/ienci/article/view/445/263> Acesso em 17 de setembro de 2019.

SEBATA, C. E; SANTOS, W; CARNEIRO, M. As imagens em textos didáticos de temas sociais em um livro didático de química: análise de seu papel pedagógico. In:V Encontro Nacional De Pesquisa Em Educação Em Ciências, p.1-11, 2005. Disponível em:< http://abrapecnet.org.br/atas_enpec/venpec/conteudo/artigos/1/pdf/p704.pdf $>$ Acesso em 21 de novembro de 2017.

TARGINO, M.G. Divulgação científica e discurso. Comunicação \& Inovação, São Caetano do Sul, v. 8, n. 15, p. 19-28, 2007. Disponível em:<

http://seer.uscs.edu.br/index.php/revista_comunicacao_inovacao/article/view/678 $>$ Acesso em 21 de outubro de 2017.

TERRAZZAN, E.A; GABANA, M. Um estudo sobre o uso de atividade didática com texto de divulgação científica em aulas de física. In: IV Encontro Nacional de Pesquisa em 
Educação em Ciências. Bauru/SP, p.1-11, 2003. Disponível em:< http://fep.if.usp.br/ profis/arquivos/ivenpec/Arquivos/Orais/ORAL172.pdf> Acesso em $24 \mathrm{de}$ novembro de 2017

XAVIER, M. E. R.; KERR, A. S. A análise do efeito estufa em textos paradidáticos e periódicos jornalísticos. Cad. Bras. Ens. Fís., v. 21, n. 3: p. 325-349, 2004. Disponível em:< https://dialnet.unirioja.es/descarga/articulo/5165513.pdf $>$ Acesso em 28 de outubro de 2017.

ZAMBON, L. B.; TERRAZAN, E. A. Estudo sobre o uso de analogias em revistas de divulgação científica. In: VI Encontro Nacional de Pesquisa em Educação em Ciências. São Paulo, p.1-8, 2007. Disponível em:< http://fep.if.usp.br/ profis/arquivos/vienpec/CR2/p1094.pdf> Acesso em 24 de novembro de 2017.

\section{SOBRE OS AUTORES}

BRUNA SARPA MICELI. Doutoranda no Programa de Pós-Graduação em Ciência, Tecnologia e Educação, localizado no Centro Federal de Educação Tecnológica Celso Suckow da Fonseca (CEFET/RJ). É mestre em Ciência, Tecnologia e Educação. Responsável pela introdução, metodologia e resultados do artigo.

IGOR LEANDRO ALVES DE CARVALHO. Doutorando no Programa de Pós-Graduação em Ciência, Tecnologia e Educação, localizado no Centro Federal de Educação Tecnológica Celso Suckow da Fonseca (CEFET/RJ). É mestre em Ciência, Tecnologia e Educação e Docente I da Secretaria de Estado de Educação do Rio de Janeiro. Responsável pela introdução e pelos resultados do artigo.

INGRID VALADARES CARMONA. É mestre em Ciência, Tecnologia e Educação pelo Programa de Pós-Graduação em Ciência, Tecnologia e Educação, localizado no Centro Federal de Educação Tecnológica Celso Suckow da Fonseca (CEFET/RJ). Responsável pelos resultados do artigo.

MARCELO BORGES ROCHA. É doutor em Ciências Biológicas (Zoologia) pela Universidade Federal do Rio de Janeiro e é professor no ensino superior no Programa de PósGraduação em Ciência, Tecnologia e Educação do Centro Federal de Educação Tecnológica Celso Suckow da Fonseca (CEFET/RJ). Responsável por conceder a ideia do artigo, por auxiliar nos resultados e por revisar o texto. 